\title{
Optimization of Culture Conditions for Secretory Production of 3-Hydroxybutyrate Oligomers Using Recombinant Escherichia coli
}

OPEN ACCESS

Edited by: Suchada Chanprateep Napathorn, Chulalongkorn University, Thailand

Reviewed by:

Zheng-Jun Li,

Beijing University of Chemical Technology, China Martin Koller. University of Graz, Austria

*Correspondence: Takeharu Tsuge tsuge.t.aa@m.titech.ac.jp

${ }^{\dagger}$ These authors have contributed equally to this work

Specialty section:

This article was submitted to Bioprocess Engineering, a section of the journal Frontiers in Bioengineering and Biotechnology

Received: 05 December 2021 Accepted: 24 January 2022 Published: 25 February 2022

Citation:

Sakurai T, Mizuno S, Miyahara Y, Hiroe A, Taguchi S and Tsuge T (2022) Optimization of Culture Conditions for Secretory Production of 3 Hydroxybutyrate Oligomers Using

Recombinant Escherichia coli. Front. Bioeng. Biotechnol. 10:829134. doi: 10.3389/fbioe.2022.829134

\author{
Tetsuo Sakurai ${ }^{1,2 \dagger}$, Shoji Mizuno ${ }^{1,2 t}$, Yuki Miyahara ${ }^{1,2}$, Ayaka Hiroe $^{3,2}$, Seiichi Taguchi $^{3}$ and \\ Takeharu Tsuge ${ }^{1,2 *}$
}

${ }^{1}$ Department of Materials Science and Engineering, Tokyo Institute of Technology, Yokohama, Japan, ${ }^{2}$ MIRAI, Japan Science and Technology Agency (JST), Saitama, Japan, ${ }^{3}$ Department of Chemistry for Life Sciences and Agriculture, Faculty of Life Sciences, Tokyo University of Agriculture, Setagaya, Japan

Poly(3-hydroxybutyrate) $[\mathrm{P}(3 \mathrm{HB})]$ is the most representative polyhydroxyalkanoate (PHA), which is a storage polyester for prokaryotic cells. $\mathrm{P}(3 \mathrm{HB})$-producing recombinant Escherichia coli secretes diethylene glycol (DEG)-terminated 3HB oligomers (3HBO-DEG) through a PHA synthase-mediated chain transfer and alcoholysis reactions with externally added DEG. The purpose of this study was to optimize the culture conditions for the secretory production of 3HBO-DEG with jar fermenters. First, the effects of culture conditions, such as agitation speed, culture temperature, culture $\mathrm{pH}$, and medium composition on 3HBO-DEG production, were investigated in a batch culture using 250-ml mini jar fermenters. Based on the best culture conditions, a fed-batch culture was conducted by feeding glucose to further increase the 3HBO-DEG titer. Consequently, the optimized culture conditions were reproduced using a 2- $L$ jar fermenter. This study successfully demonstrates a high titer of $3 \mathrm{HBO}-\mathrm{DEG}$, up to $34.8 \mathrm{~g} / \mathrm{L}$, by optimizing the culture conditions, showing the feasibility of a new synthetic strategy for $\mathrm{PHA}$-based materials by combining secretory oligomer production and subsequent chemical reaction.

Keywords: class IV PHA synthase, oligomer, secretion, fed-batch culture, alcoholysis, chain transfer reaction, 3hydroxybutyrate

\section{INTRODUCTION}

Polyhydroxyalkanoate (PHA) is a thermoplastic polyester that accumulates in microbial cells as an energy storage substance from renewable biomasses such as sugars and vegetable oils (Sudesh et al., 2000). Utilizing PHA as an alternative material to petroleum plastics is attracting considerable attention; this is because petroleum plastics are non-biodegradable in nature and cause environmental pollution and ecosystem destruction. PHA, which is microbially produced, has excellent biodegradability in various environments, including marine environments (Suzuki et al., 2021), making it an attractive material for many scientists and engineers. PHAs are promising materials for ensuring sustainability and renewability (Sivashankari et al., 2021; Taguchi and Matsumoto, 2021). 
Poly(3-hydroxybutyrate) $[\mathrm{P}(3 \mathrm{HB})]$, which is one of the most representative PHAs, has high strength and a high melting point that is comparable to polypropylene (Sudesh et al., 2000). However, owing to its brittleness and high production cost, $\mathrm{P}(3 \mathrm{HB})$ is difficult to use as a commodity plastic material. Numerous studies have been conducted to make $\mathrm{P}(3 \mathrm{HB})$ a more practical material through copolymerization. The brittleness of $\mathrm{P}(3 \mathrm{HB})$ can be improved by introducing second monomer units such as 3hydroxyvalerate, 3-hydroxyhexanoate, 3-hydroxy-4methylvalerate, and 4-hydroxybutyrate (Sudesh et al., 2000; Tanadchangsaeng et al., 2009). The presence of these second monomer units in the $\mathrm{P}(3 \mathrm{HB})$ sequence prevents the crystallization of $\mathrm{P}(3 \mathrm{HB})$, thereby resulting in increased flexibility of the material. Although copolymerization can improve these mechanical properties, it does not contribute to reducing the production cost of PHA.

$\mathrm{P}(3 \mathrm{HB})$-producing recombinant Escherichia coli secretes a small amount of $3 \mathrm{HB}$ oligomers (3HBO) through a PHA synthase-mediated chain transfer (CT) reaction (Miyahara et al., 2019; Hiroe et al., 2021). The CT reaction is induced via endogenous ethanol, and elongating polymer/oligomer chains are released by the alcoholysis of thioester bonds between PHA synthase-polymer/oligomer complexes (Hiroe et al., 2013; Tsuge, 2016). Thus, ethanol is conjugated to the carboxyl terminal of $3 \mathrm{HBO}$ by functioning as a CT agent.

By contrast, the externally and abundantly added alcohol compounds such as ethanol and ethylene glycol also function as CT agents for PHA synthesis (Utsunomia et al., 2017a; Mizuno et al., 2021; Nduko and Taguchi, 2021). Among the alcohol compounds tested so far, the externally added diethylene glycol (DEG) showed the highest efficacy as a $\mathrm{CT}$ agent, resulting in the secretory production of DEGterminated $3 \mathrm{HBO}$ (3HBO-DEG) with a titer of $4.32 \mathrm{~g} / \mathrm{L}$ (Hiroe et al., 2021). The 3HBO-DEG purified from the culture supernatant can be used as a macromonomer for the synthesis of $3 \mathrm{HBO}$-based polyurethane by reacting with diisocyanate (Hiroe et al., 2021). The 3HBO-based polyurethane is an amorphous polymer with a high transparency, and can counteract the brittleness of $\mathrm{P}(3 \mathrm{HB})$. Thus, microbial $3 \mathrm{HBO}-\mathrm{DEG}$ has a great potential for usage in the synthesis of novel $3 \mathrm{HBO}$-based polymers.

Secretory production of $3 \mathrm{HBO}$ is a cost-effective approach when compared with conventional intracellular $\mathrm{P}(3 \mathrm{HB})$ production, as $3 \mathrm{HBO}$ can be easily purified from the culture supernatant via the solvent extraction method (Hiroe et al., 2021). However, to further enhance the cost-effectiveness of secretory production, it is necessary to increase the titer of $3 \mathrm{HBO}$ in the culture broth.

The purpose of this study was to optimize the culture conditions of E. coli BW25113 $\Delta a d h E$ harboring pGEMphaRC $C_{\mathrm{YB} 4} A B$ for the secretory production of $3 \mathrm{HBO}-\mathrm{DEG}$ with jar fermenters. First, the effects of culture conditions, such as agitation speed, culture temperature, culture $\mathrm{pH}$, and medium composition, on 3HBO-DEG production were investigated in a batch culture using 250-ml mini jar fermenters. Subsequently, a fed-batch culture was conducted by feeding glucose to further increase the $3 \mathrm{HBO}-\mathrm{DEG}$ titer. Consequently, the optimized culture conditions were reproduced using a $2-\mathrm{L}$ jar fermenter. This study successfully demonstrates the production of high $3 \mathrm{HBO}-\mathrm{DEG}$ tires up to $34.8 \mathrm{~g} / \mathrm{L}$ by optimizing culture conditions.

\section{MATERIALS AND METHODS}

\section{Bacterial Strains and Plasmids}

E. coli BW25113 $\mathrm{adhE}$ (JW1228), an alcohol dehydrogenase gene $(a d h E)$-disrupted strain, was used as the host strain for oligomer production throughout the study. This strain was provided by the National BioResource Project (NBRP), Japan, from the Keio Collection (Baba et al., 2006). The plasmid pGEMphaR $C_{\mathrm{YB} 4} A B$ carrying PHA synthase genes (phaRC $C_{\mathrm{YB} 4}$ (Tomizawa et al., 2011)), a 3-ketothiolase gene (phaA from Ralstonia eutropha H16 (Pohlmann et al., 2006)), and an acetoacetyl-CoA reductase gene ( $p h a B$ from $R$. eutropha $\mathrm{H} 16$ (Pohlmann et al., 2006)) were used for 3HBO-DEG production. The synthesis pathway of $3 \mathrm{HBO}-\mathrm{DEG}$ is shown in Figure $\mathbf{1 .}$

\section{Batch Culture for 3HBO-DEG Production}

For pre-culturing, the recombinant E. coli BW25113 $\Delta a d h E$ harboring pGEM-phaR $C_{\mathrm{YB} 4} A B$ was grown in a Lysogeny Broth (LB) medium $(10 \mathrm{~g} / \mathrm{L}$ Bacto tryptone, $5 \mathrm{~g} / \mathrm{L}$ Bacto yeast extract, $10 \mathrm{~g} / \mathrm{L} \mathrm{NaCl}$ ) at $30^{\circ} \mathrm{C}$ overnight. The seed culture was inoculated at $1 \%(\mathrm{v} / \mathrm{v})$ of the initial working volume into a 250-ml jar fermenter (Bio Jr8, Able Corp., Tokyo, Japan) with $100 \mathrm{ml} \mathrm{LB}$ medium containing $40 \mathrm{~g} / \mathrm{L}$ glucose (Glc) and $50 \mathrm{~g} / \mathrm{L}$ DEG (Kanto Chem. Co., Inc., Tokyo, Japan). To maintain the plasmid pGEMphaRC $C_{\mathrm{YB} 4} A B$ in the cells, ampicillin $(100 \mathrm{mg} / \mathrm{L})$ was added to the medium. A $500 \mu \mathrm{l}$ of $1 \%(\mathrm{w} / \mathrm{v}$ ) antifoam 204 (SigmaAldrich, St. Louis, USA) solution was added into the initial culture medium to prevent the foam generation during cultivation.

To optimize the fermentation conditions, the effects of the agitation speed $(150-1,200 \mathrm{rpm})$, culture temperature $\left(26-36^{\circ} \mathrm{C}\right)$, culture $\mathrm{pH}$ ( $\mathrm{pH} 5-8$ or non-control), $\mathrm{NaCl}$ concentration (10-50 g/L in LB medium), type of medium [LB, TB, MR (Y1), and MR (Y5) media] on 3HBO-DEG production were investigated in batch culture operations. The medium composition, other than the LB medium, was as follows: The Terrific broth (TB) medium (Iliev et al., 2018) contained $12 \mathrm{~g} / \mathrm{L}$ tryptone, $24 \mathrm{~g} / \mathrm{L}$ yeast extract, $9.4 \mathrm{~g} / \mathrm{L} \mathrm{K}_{2} \mathrm{HPO}_{4}$, and $2.2 \mathrm{~g} / \mathrm{L}$ $\mathrm{KH}_{2} \mathrm{PO}_{4}$ dissolved in water. The modified $\mathrm{R}(\mathrm{MR})$ medium plus yeast extract [MR (Y1) or MR (Y5) medium] contained $13.5 \mathrm{~g} / \mathrm{L} \mathrm{KH}_{2} \mathrm{PO}_{4}, 4 \mathrm{~g} / \mathrm{L}\left(\mathrm{NH}_{4}\right)_{2} \mathrm{HPO}_{4}, 1.4 \mathrm{~g} / \mathrm{L} \mathrm{MgSO}_{4} \cdot 7 \mathrm{H}_{2} \mathrm{O}$, $1.7 \mathrm{~g} / \mathrm{L}$ citric acid, Bacto yeast extract $(1 \mathrm{~g} / \mathrm{L}$ or $5 \mathrm{~g} / \mathrm{L})$, and $10 \mathrm{ml} / \mathrm{L}$ trace metal solution dissolved in water $(\mathrm{pH}$ 7.0) (Mohd Fadzil et al., 2018; Mizuno et al., 2021). The trace metal solution contained $10 \mathrm{~g} / \mathrm{L} \mathrm{FeSO}_{4} \cdot 7 \mathrm{H}_{2} \mathrm{O}, 2 \mathrm{~g} / \mathrm{L} \mathrm{CaCl}_{2}$, $2.2 \mathrm{~g} / \mathrm{L} \quad \mathrm{ZnSO}_{4} \cdot 7 \mathrm{H}_{2} \mathrm{O}, \quad 0.5 \mathrm{~g} / \mathrm{L} \quad \mathrm{MnSO}_{4} \cdot 4 \mathrm{H}_{2} \mathrm{O}, \quad 1 \mathrm{~g} / \mathrm{L}$ $\mathrm{CuSO}_{4} \cdot 5 \mathrm{H}_{2} \mathrm{O}, \quad 0.1 \mathrm{~g} / \mathrm{L} \quad\left(\mathrm{NH}_{4}\right)_{6} \mathrm{Mo}_{7} \mathrm{O}_{24} \cdot 4 \mathrm{H}_{2} \mathrm{O}$ and $0.02 \mathrm{~g} / \mathrm{L}$ 


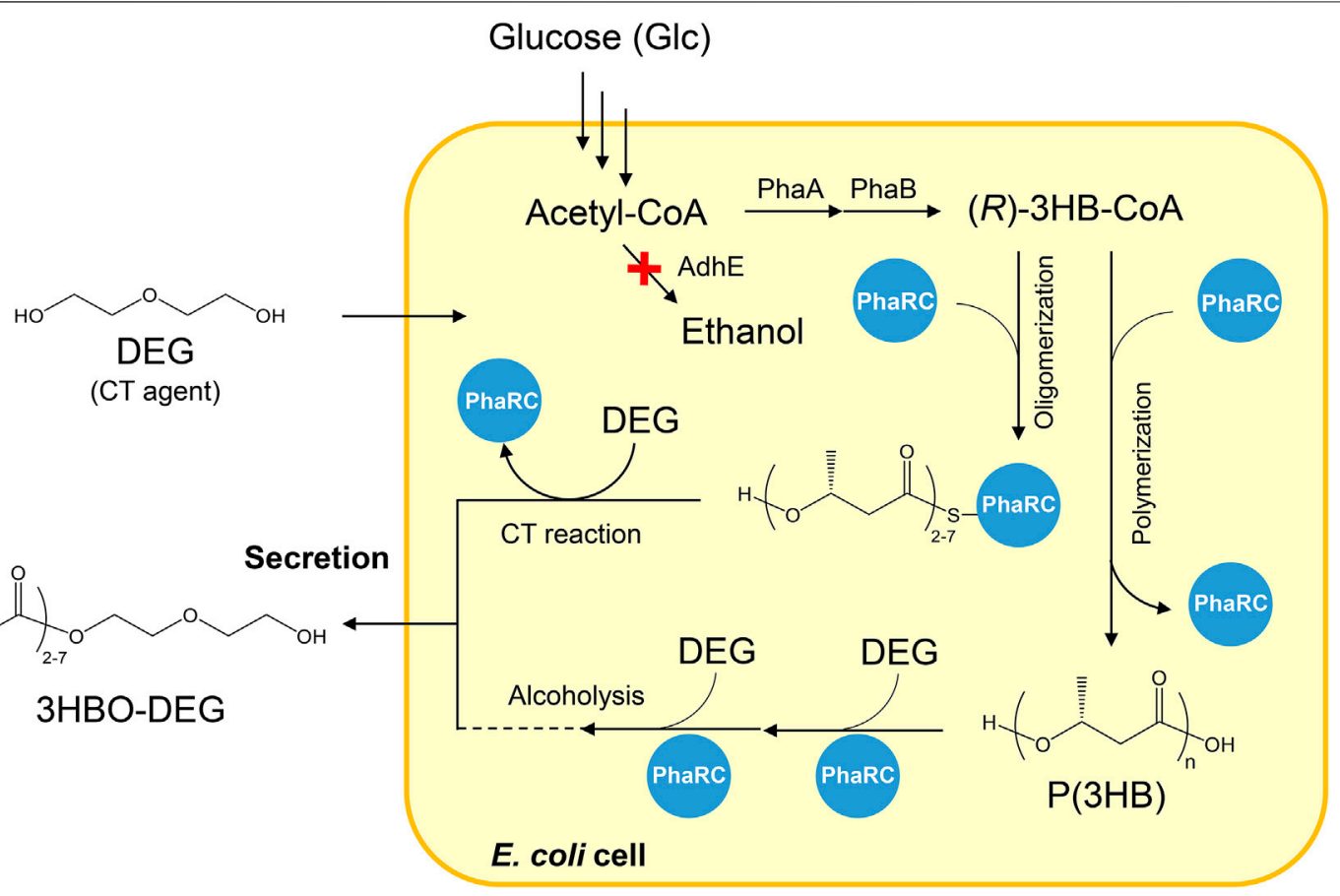

FIGURE 1 | Secretary production of 3HBO-DEG via E. coli BW25113 $\Delta$ adhE harboring pGEM-phaRCYB4AB. AdhE: alcohol dehydrogenase, PhaA: 3-ketothiolase from $R$. eutropha H16, PhaB: acetoacetyl-CoA reductase from $R$. eutropha H16, PhaRC: PHA synthase from B. cereus YB-4, 3HB: 3-hydroxybutyrate, DEG: diethylene glycol, CT: chain transfer.

$\mathrm{Na}_{2} \mathrm{~B}_{4} \mathrm{O}_{7} \cdot 10 \mathrm{H}_{2} \mathrm{O}$ dissolved in $0.1 \mathrm{M} \mathrm{HCl}$. For the $\mathrm{pH}$-stat culture, $1 \mathrm{~N} \mathrm{NaOH}$ or $1 \mathrm{~N} \mathrm{HCl}$ was added automatically.

\section{Fed-Batch Culture for 3HBO-DEG Production}

To enhance $3 \mathrm{HBO}-\mathrm{DEG}$ production, fed-batch cultures with a 250-ml mini jar fermenter were conducted by feeding glucose at a constant rate of $1.25 \mathrm{~g}-\mathrm{Glc} /(\mathrm{L} \cdot \mathrm{h})$ after $24 \mathrm{~h}$ of cultivation using a peristaltic pump SMP-21S (EYELA, Tokyo, Japan). For fed-batch cultures with TB and MR (Y5) media, the glucose feeding rate was temporarily changed to $2.5 \mathrm{~g}$-Glc/ $(\mathrm{L} \cdot \mathrm{h})$ depending on the glucose consumption rate. A feed solution composed of $500 \mathrm{~g} / \mathrm{L}$ glucose, $15 \mathrm{~g} / \mathrm{L} \mathrm{MgSO}_{4} \cdot 7 \mathrm{H}_{2} \mathrm{O}$, and $0.25 \mathrm{~g} / \mathrm{L}$ thiamine hydrochloride was used. The fed-batch cultures were performed at $100 \mathrm{ml}$ of the initial working volume, $100 \mathrm{ml} / \mathrm{min}$ of air flow (1 vvm), $600 \mathrm{rpm}$ of agitation speed, and a culture temperature of $30^{\circ} \mathrm{C}$ without $\mathrm{pH}$ control.

The fed-batch culture was scaled up using a 2-L scale jar fermenter (Bioneer MDL-8C, B.E. Marubishi, Tokyo, Japan). A $1 \mathrm{~L}$ of LB medium supplemented with glucose (40 g/L) and DEG $(50 \mathrm{~g} / \mathrm{L})$ was used as an initial culture. The feed solution was manually fed at regular intervals to maintain low glucose concentrations. A feed solution composed of $700 \mathrm{~g} / \mathrm{L}$ glucose, $15 \mathrm{~g} / \mathrm{L} \mathrm{MgSO}_{4} \cdot 7 \mathrm{H}_{2} \mathrm{O}$, and $0.25 \mathrm{~g} / \mathrm{L}$ thiamine hydrochloride was used (Wang and Lee, 1997; Kahar et al., 2005). The culture pH was not controlled, and the air flow was set at $1 \mathrm{~L} / \mathrm{min}(1 \mathrm{vvm})$.
Unless otherwise indicated, culture conditions were the same as that of the $250-\mathrm{ml}$ scale mini jar culture.

\section{Analytical Methods}

Following cultivation, the cells were collected via centrifugation $\left(5,960 \times \mathrm{g}, 10 \mathrm{~min}, 4^{\circ} \mathrm{C}\right)$, washed twice with pure water to remove the remaining culture medium components, and then lyophilized. The culture supernatant was collected for $3 \mathrm{HBO}$ and $3 \mathrm{HB}$ monomer measurements.

Extracellular $3 \mathrm{HBO}$ was quantified using the culture supernatant. The culture supernatant of recombinant $E$. coli strain was analyzed before and after acid hydrolysis (Hiroe et al., 2021). One hundred $\mu \mathrm{l}$ of $4 \mathrm{M} \mathrm{HCl}$ was added to $100 \mu \mathrm{L}$ of the culture supernatant and incubated at $100^{\circ} \mathrm{C}$ for $2 \mathrm{~h}$ to hydrolyze the oligomeric $3 \mathrm{HB}$ component, after which the reaction mixture was properly neutralized with $\mathrm{NaOH}$ solution. The amount of $3 \mathrm{HB}$ in the culture supernatant was measured using an enzyme assay with D$3 \mathrm{HB}$ enzyme assay kits (J.K. International, Tokyo, Japan). Therefore, the $3 \mathrm{HB}-\mathrm{DEG}$ titer was described as volumetric weight excluding DEG in this study.

The intracellular $\mathrm{P}(3 \mathrm{HB})$ content of the dried cells was determined via gas chromatography (GC) using a GC-2014s (Shimadzu, Kyoto, Japan) equipped with a flame ionization detector (FID). Samples for GC analysis were prepared from lyophilized cells via methanolysis using 15:85 v/v\% sulfuric acid/ methanol solution and chloroform at $100^{\circ} \mathrm{C}$ for $140 \mathrm{~min}$.

The concentration of glucose in the culture supernatants was assayed using the Glucose CII-Test kit (Fujifilm Wako Pure 

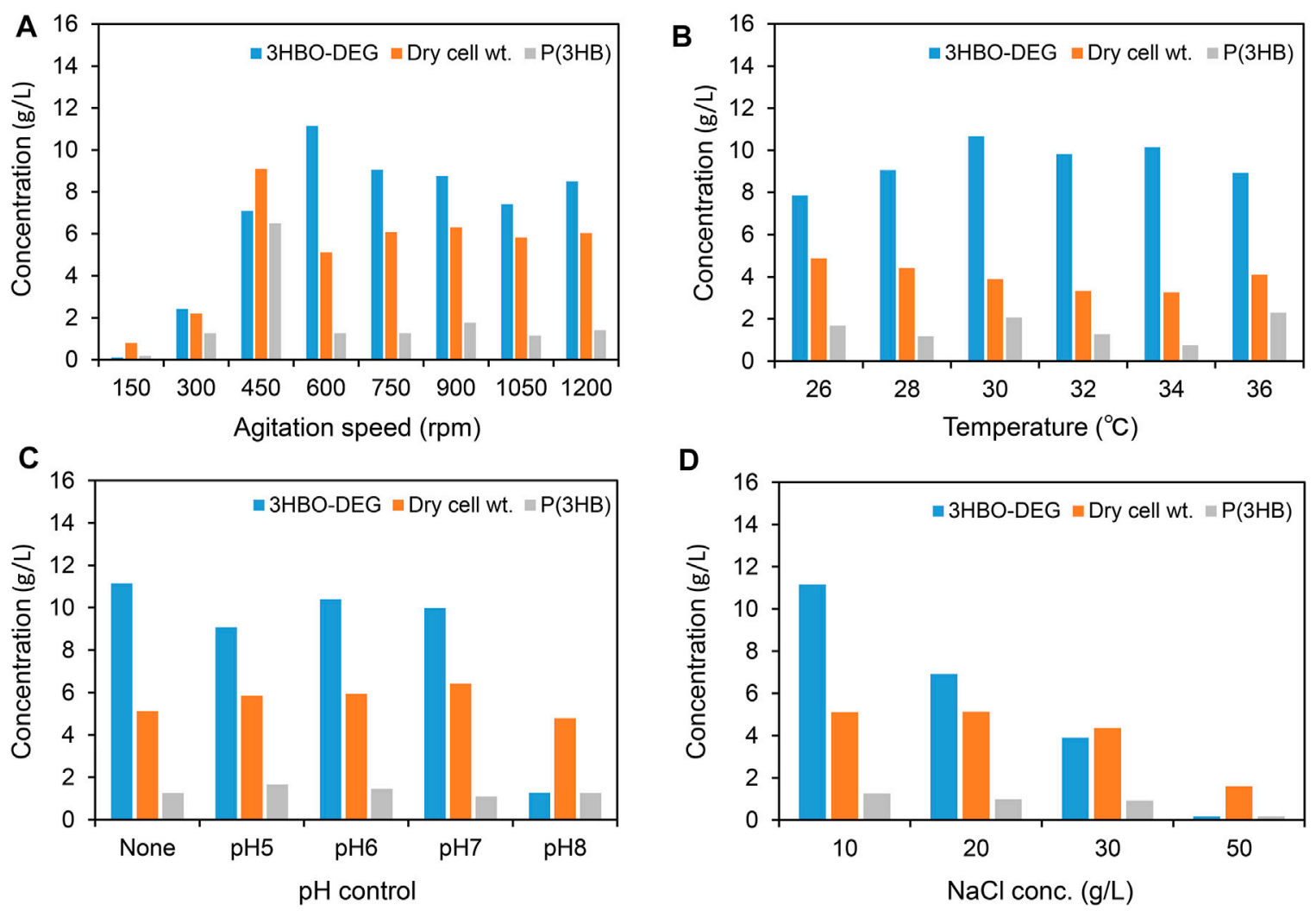

FIGURE 2 |Batch cultures of recombinant E. coli BW25113 $\Delta$ adhE harboring pGEM-phaRCYB4AB with a 250-ml mini jar fermenter. Cells were cultured in a $100 \mathrm{ml}$ LB medium supplemented with $40 \mathrm{~g} / \mathrm{L}$ glucose and $50 \mathrm{~g} / \mathrm{L} \mathrm{DEG}$ for $48 \mathrm{~h}$ [except for (B), $96 \mathrm{~h}$ ]. The effects of the (A) agitation speed, (B) culture temperature, (C) pH control ( $\mathrm{pH}$ was regulated automatically by adding $1 \mathrm{~N} \mathrm{NaOH}$ or $1 \mathrm{~N} \mathrm{HCl}$ for $\mathrm{pH}$-stat culture), and (D) $\mathrm{NaCl}$ concentration on 3HBO-DEG secretion were examined. Unless otherwise indicated, culture conditions were $600 \mathrm{rpm}, 1 \mathrm{vvm}, 30^{\circ} \mathrm{C}, \mathrm{pH}$ uncontrolled, and $10 \mathrm{~g} / \mathrm{L} \mathrm{NaCl}$.

Chem., Osaka, Japan). The measurement sample was prepared by diluting the culture supernatant with pure water.

The 3HBO-DEG secreted in the culture supernatant was extracted using chloroform, and the mixture was stirred for $1 \mathrm{~h}$ at room temperature. The chloroform was recovered from the separated layers and washed three times with an equal volume of water to remove the remaining culture medium components. After the washing, chloroform was collected and lyophilized to obtain purified $3 \mathrm{HBO}$ samples.

The extracted oligomer samples were dissolved in methanol and passed through a polytetrafluoroethylene (PTFE) filter before being injected into the electrospray ionization time-of-flight mass spectrometry (ESI TOF-MS) system (micrOTOFII, Bruker Daltonics Co.).

\section{RESULTS AND DISCUSSION Optimization of 3HBO-DEG Production in Batch Culture}

Our previous study showed a production of $4.32 \mathrm{~g} / \mathrm{L}$ of $3 \mathrm{HBO}-$ DEG in a shake flask culture, with $50 \mathrm{~g} / \mathrm{L}$ of DEG added into the LB culture medium (Hiroe et al., 2021). To optimize the $3 \mathrm{HBO}-\mathrm{DEG}$ production, batch cultures of recombinant $E$. coli
BW25113 $\triangle a d h E$ harboring pGEM-phaRC $C_{\mathrm{YB} 4} A B$, which expresses the PHA synthase gene (phaRC $\left.C_{\mathrm{YB} 4}\right)$ from Bacillus cereus YB-4 and the (R)-3-hydroxybutyryl-coenzyme A (3HB-CoA) supplier genes (phaAB) from $R$. eutropha, were conducted using a $250-\mathrm{ml}$ mini jar fermenter (BioJr.8). The $\mathrm{PhaRC}_{\mathrm{YB} 4}$ used in this study is a class IV PHA synthase (Tsuge et al., 2015); it has high alcoholysis activity in addition to the CT reaction activity (Hyakutake et al., 2014) and is an enzyme capable of producing high amounts of $3 \mathrm{HBO}$ (Figure 1). The $\mathrm{CT}$ and the alcoholysis reactions both produce the oligomers terminally modified with alcohols, but the occurring phase of each reaction is different. The $\mathrm{CT}$ reaction occurs during the polymerization process of $\mathrm{P}(3 \mathrm{HB})$, whereas the alcoholysis reaction occurs after the polymerization of $\mathrm{P}(3 \mathrm{HB})$. The $\triangle a d h E$ strain was used in this study to prevent $3 \mathrm{HBO}$ end modification via endogenous ethanol (Leonardo et al., 1993; Hiroe et al., 2013).

First, to examine the effect of agitation speed on $3 \mathrm{HBO}$ DEG production, the agitation speed was varied in the range of $150-1,200 \mathrm{rpm}$ at a constant air flow $(100 \mathrm{ml} / \mathrm{min})$. As shown in Figure 2A, the agitation speed had a definite effect on both cell growth and 3HBO-DEG production during cultivation. Improved growth was observed at agitation speeds of over $450 \mathrm{rpm}$, whereas the highest 


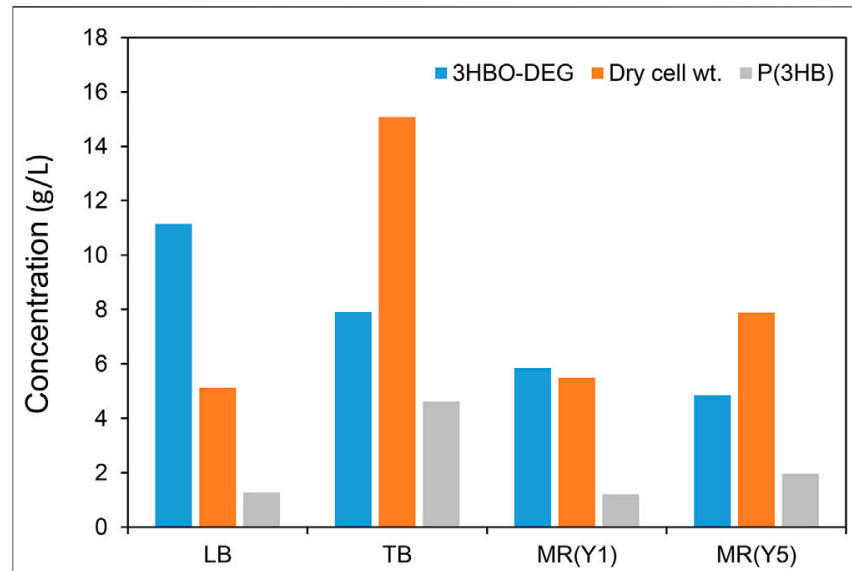

FIGURE 3 | Effect of culture media on 3HBO-DEG secretion in the batch culture with a 250-ml mini jar fermenter. Recombinant E. coli BW25113 $\Delta$ adhE harboring the pGEM-phaRC $C_{\mathrm{YB} 4} A B$ was cultured in a $100 \mathrm{ml}$ culture medium supplemented with $40 \mathrm{~g} / \mathrm{L}$ glucose and $50 \mathrm{~g} / \mathrm{L} \mathrm{DEG}$ at $30^{\circ} \mathrm{C}, 1 \mathrm{vvm}$ $600 \mathrm{rpm}, \mathrm{pH}$ uncontrolled for $48 \mathrm{~h}$.

$3 \mathrm{HBO}-\mathrm{DEG}$ production of $11.2 \mathrm{~g} / \mathrm{L}$ was observed at $600 \mathrm{rpm}$. By contrast, $\mathrm{P}(3 \mathrm{HB})$ accumulation in the cells was reduced from $71.3 \mathrm{wt} \%$ to $24.6 \mathrm{wt} \%$ by increasing the agitation speed from 450 to $600 \mathrm{rpm}$. According to the technical information of the fermenter supplier, the volumetric oxygen transfer coefficients $\left(k_{\mathrm{La}}\right)$ at $450 \mathrm{rpm}$ and $600 \mathrm{rpm}$ were approximately 50 and $400 \mathrm{~h}^{-1}$, respectively. This suggestes that aerobic culture conditions promoted oligomer production rather than $\mathrm{P}(3 \mathrm{HB})$ accumulation, due to the increased occurrence of CT and alcoholysis reactions. Additionally, since larger size of oligomers were remained in the cells (Hiroe et al., 2021), hydrophobic oligomers trapped in the cell membrane (Roman et al., 2020) may have been pushed out into the extracellular space by vigorous agitation. Based on the result, the agitation speed of $600 \mathrm{rpm}$ was used in the subsequent cultures.

To examine the effect of culture temperature on oligomer production, the culture temperature was varied between 26 and $36^{\circ} \mathrm{C}$ (Figure 2B). Unless otherwise indicated, the agitation speed and air flow rate in later cultures were set at $600 \mathrm{rpm}$ and $100 \mathrm{ml} /$ $\min (1 \mathrm{vvm})$, respectively. The strain showed the highest oligomer production at $30^{\circ} \mathrm{C}$; however, similar oligomer titers were obtained between 30 and $34^{\circ} \mathrm{C}$. In general, PHA synthases show maximum activity at around $30^{\circ} \mathrm{C}$, whereas the growth of E. coli is optimal at $37^{\circ} \mathrm{C}$ (Agus et al., 2006; Agus et al., 2010; Tomizawa et al., 2011; Mizuno et al., 2021). Therefore, a high oligomer titer was obtained at between these optimum temperatures.

Subsequently, $\mathrm{pH}$-stat cultures at $\mathrm{pH}$ 5-8 were conducted by automatically adding $1 \mathrm{~N} \mathrm{NaOH}$ and $1 \mathrm{~N} \mathrm{HCl}$, together with a $\mathrm{pH}$-uncontrolled culture (Figure 2C). Among $\mathrm{pH}$-stat cultures, a high titer of $10.4 \mathrm{~g} / \mathrm{L}$ oligomer was obtained by culturing at $\mathrm{pH} 6$, and relatively high yields were obtained between $\mathrm{pH}$ 5-7. However, the highest titer of $11.1 \mathrm{~g} / \mathrm{L}$ oligomer was obtained under $\mathrm{pH}$ uncontrolled conditions.
The change in $\mathrm{pH}$ during $\mathrm{pH}$ uncontrolled cultivation is described later.

In our previous study (Mizuno et al., 2021), the secretion of lactate-based oligomers was enhanced by increasing the $\mathrm{NaCl}$ concentration in the LB medium. Therefore, to investigate the osmotic effect of $\mathrm{NaCl}$ on 3HBO-DEG secretion, the $\mathrm{NaCl}$ concentration in the medium was varied between 10 and $50 \mathrm{~g} / \mathrm{L}$. However, the $3 \mathrm{HBO}-\mathrm{DEG}$ titer and cell growth were negatively correlated with the $\mathrm{NaCl}$ concentration (Figure 2D). Unlike lactate-based oligomer production, the osmotic effect of $\mathrm{NaCl}$ had no positive impact on $3 \mathrm{HBO}-\mathrm{DEG}$ production.

\section{Exploring Culture Medium Suitable for 3HBO-DEG Production}

In order to explore the culture medium suitable for 3HBO-DEG production, the other three media, TB, MR (Y1), and MR (Y5), were also examined without controlling the culture $\mathrm{pH}$. The TB medium is a more nutritious medium than the LB medium, whereas MR medium is a mineral medium (Wang and Lee, 1997; Kahar et al., 2005). The MR (Y1) and MR (Y5) media used in this study contained $1 \mathrm{~g} / \mathrm{L}$ and $5 \mathrm{~g} / \mathrm{L}$ yeast extract, respectively, because the secretion of 3HBO-DEG did not occur with the MR medium alone. The culture results are shown in Figure 3. The TB medium facilitated higher cell growth and higher $\mathrm{P}(3 \mathrm{HB})$ accumulation than $\mathrm{LB}$ medium owing to an abundance of nutrients. However, $3 \mathrm{HBO}-\mathrm{DEG}$ secretion was not enhanced, indicating that cell growth was prioritized in the TB medium. In addition, 3HBO-DEG secretion was not enhanced in the MR (Y1) and MR (Y5) media. Among the media tested, the LB medium exhibited the highest 3HBO-DEG titer and the lowest intracellular $\mathrm{P}(3 \mathrm{HB})$ accumulation. To increase the yield of 3HBO-DEG, intracellular $\mathrm{P}(3 \mathrm{HB})$ accumulation had to be maintained at low levels. Besides, the following experiments were carried out by using LB medium.

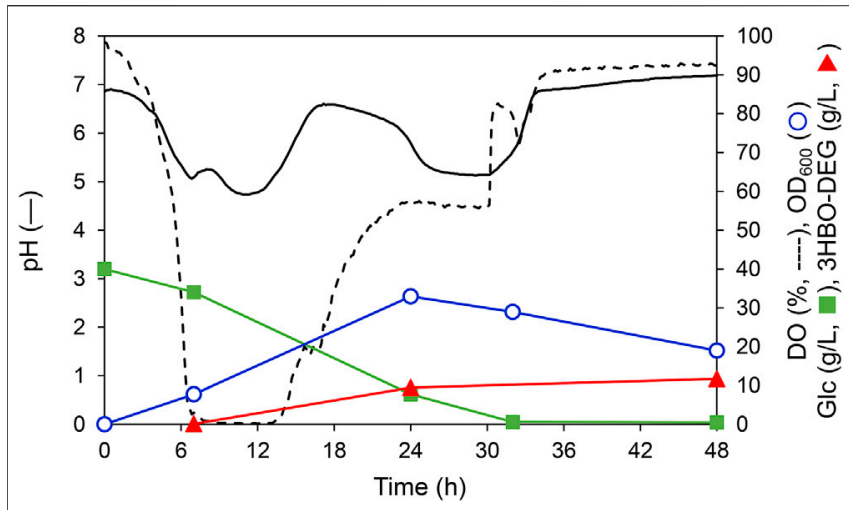

FIGURE 4 | Batch culture of recombinant E. coli BW25113 $\Delta$ adhE harboring pGEM-phaRC $C_{\mathrm{YB} 4} A B$ with a $250-\mathrm{ml}$ mini jar fermenter. The cells were cultured in $100 \mathrm{ml}$ LB medium supplemented with $40 \mathrm{~g} / \mathrm{L}$ glucose and $50 \mathrm{~g} / \mathrm{L} \mathrm{DEG}$ at $30^{\circ} \mathrm{C}, 1 \mathrm{vvm}, 600 \mathrm{rpm}, \mathrm{pH}$ uncontrolled for $48 \mathrm{~h}$.

Triangles denote extracellular $3 \mathrm{HBO}-\mathrm{DEG}$ concentrations, squares denote the glucose concentration, circles denote cell growth $\left(\mathrm{OD}_{600}\right)$, the solid line denotes $\mathrm{pH}$, and the dashed line denotes dissolved oxygen (DO). 


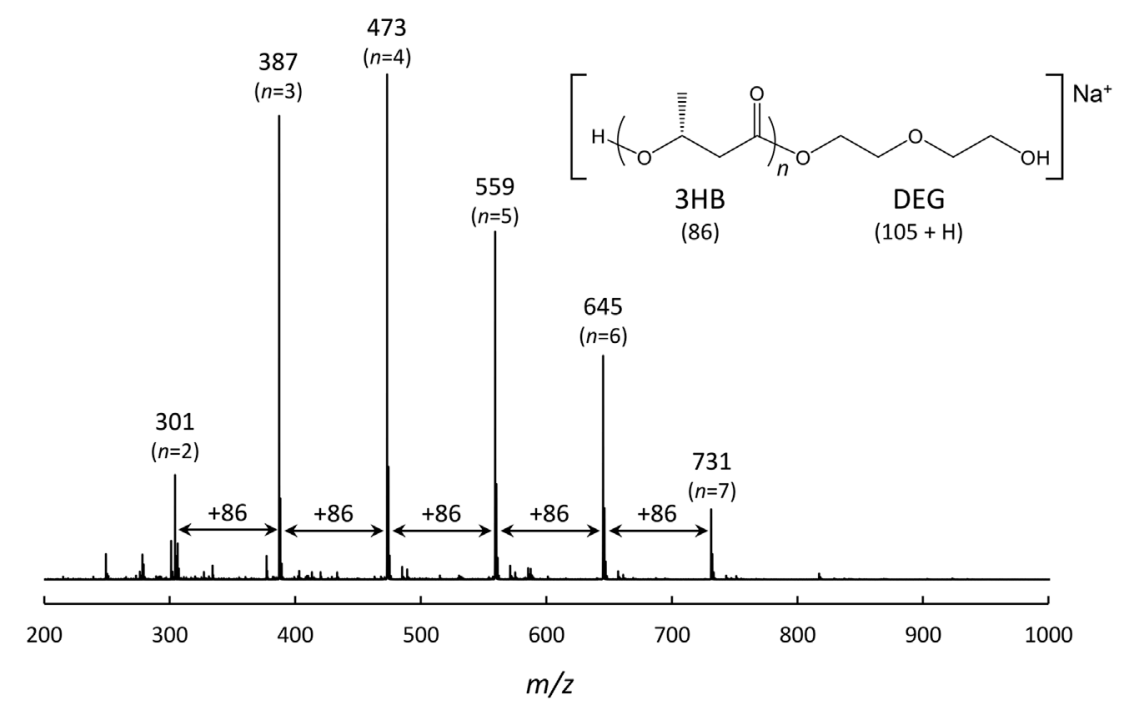

FIGURE 5 | ESI TOF-MS spectrum of 3HBO-DEG produced by the batch culture of $E$. coli BW25113 $\triangle$ adhE harboring pGEM-phaRCYB $4 A B$ in LB medium, $30^{\circ} \mathrm{C}, 1$ wm, 600 rpm, pH uncontrolled for $48 \mathrm{~h}$. ESI TOF-MS analysis was performed in the positive mode. The peak interval of $m / z 86$ indicates a $3 \mathrm{HB}$ repeating unit.

\section{Time Course of pH-Uncontrolled Batch Culture Using LB Medium}

Optimization analysis revealed that $3 \mathrm{HBO}-\mathrm{DEG}$ production could be maximized at a $600 \mathrm{rpm}$ agitation speed, $1 \mathrm{vvm}$, and $30^{\circ} \mathrm{C}$ in the $\mathrm{LB}$ medium without controlling the culture $\mathrm{pH}$. The time course under this culture condition is shown in Figure 4. In this culture, $40 \mathrm{~g} / \mathrm{L}$ glucose was consumed in $32 \mathrm{~h}$. The dissolved oxygen (DO) concentration decreased to almost zero after $6 \mathrm{~h}$ and began to increase after $14 \mathrm{~h}$. Because the DO concentration was almost zero during $6-14 \mathrm{~h}$ of culturing, it is presumed that organic acids such as acetic acid, formic acid and succinic acid were generated by anaerobic metabolism (Hiroe et al., 2013; Förster and Gescher, 2014), and the $\mathrm{pH}$ of the culture broth decreased. In contrast, the $\mathrm{pH}$ increased after $14 \mathrm{~h}$ of culturing, which was likely caused by the consumption of these organic acids by the cells due to glucose deficiency. The culture $\mathrm{pH}$ changed between 4.7 and 7.2 during cultivation without $\mathrm{pH}$ control. For $3 \mathrm{HBO}-\mathrm{DEG}$, secretion was not observed untill $6 \mathrm{~h}$ of cultivation. Consequently, the 3HBO-DEG titers increased to $9.5 \mathrm{~g} / \mathrm{L}$ and $11.2 \mathrm{~g} / \mathrm{L}$ at $24 \mathrm{~h}$ and $48 \mathrm{~h}$ of cultivation, respectively. Further extension of culture had no effect on increasing the $3 \mathrm{HBO}-\mathrm{DEG}$ titer, suggesting that oligomer production by alcoholysis in the stationary phase cells did not proceed efficiently. Therefore, culturing while maintaining CT reaction activity and alcoholysis activity of PHA synthase for a long time may lead to higher oligomer yield.

\section{Molecular Mass Analysis of the Secreted 3HBO-DEG}

ESI TOF-MS analysis was performed to measure the molecular mass of 3HBO-DEG obtained by secretory production. Through solvent extraction with chloroform, the sample was extracted from the supernatant of the culture (Figure 4). The ESI TOF-MS spectrum is shown in Figure 5. 3HBO-DEG was detected as a $\mathrm{Na}^{+}$adduct with $\mathrm{m} / z$ 300-800. These peaks corresponded to the molecular mass of the 2- to 7-mers $3 \mathrm{HB}$ terminated with $\mathrm{DEG}$, thereby confirming the production of terminally modified oligomers. The molecular mass of secreted oligomers was probably regulated by the cell membrane of the host $E$. coli, which limited the size of secretion outside the cell. The molecular mass of 3HBO-DEG was consistent with that reported in our previous study (Hiroe et al., 2021). The secretory produced oligomer, which showed a high terminal modification frequency with DEG, can be preferably used as a macromonomer for synthesizing poly (ester-urethane) materials, as described previously (Utsunomia et al., 2017b; Hiroe et al., 2021; Nduko and Taguchi, 2021).

\section{Enhanced 3HBO-DEG Production by Fed-Batch Culture}

To further increase the 3HBO-DEG titer, fed-batch cultures using $\mathrm{LB}, \mathrm{TB}$, and MR (Y5) media were performed through feeding glucose. To this end, glucose solution was fed at $1.25 \mathrm{~g}$-Glc/(L.h) after $24 \mathrm{~h}$ of culturing. However, when glucose consumption by the cells was vigorous, the feed rate was temporarily increased to $2.5 \mathrm{~g}-\mathrm{Glc} /(\mathrm{L} \cdot \mathrm{h})$. Other culture conditions were the same as for the batch culture ( $\mathrm{pH}$ uncontrolled, agitation speed $600 \mathrm{rpm}, 1 \mathrm{vvm}$ ). The culture results are listed in Table $\mathbf{1}$, and the culture time course using LB medium is shown in Figure $\mathbf{6}$ as a representative example. For the $\mathrm{LB}$ medium, the $3 \mathrm{HBO}$ DEG titer increased from $3.7 \mathrm{~g} / \mathrm{L}$ to $30.4 \mathrm{~g} / \mathrm{L}$ between 24 and $120 \mathrm{~h}$. During this period, the culture $\mathrm{pH}$ was unchanged at approximately 4.5 , which was a much lower 
TABLE 1 | Secretory production of 3HBO-DEG via E. coli BW25113 $\Delta a d h E$ harboring pGEM-phaRC $C_{\mathrm{YB} 4} A B$.

\begin{tabular}{|c|c|c|c|c|c|c|c|c|c|}
\hline $\begin{array}{l}\text { Operation } \\
\text { mode }\end{array}$ & $\begin{array}{c}\text { Culture } \\
\text { equipment }\end{array}$ & $\begin{array}{c}\text { Initial } \\
\text { working } \\
\text { vol. } \\
\text { (ml) }\end{array}$ & $\begin{array}{l}\text { Culture } \\
\text { medium }\end{array}$ & $\begin{array}{c}\text { Glc } \\
\text { consumption } \\
(\mathrm{g} / \mathrm{L})\end{array}$ & $\begin{array}{l}\text { Culture } \\
\text { time } \\
\text { (h) }\end{array}$ & $\begin{array}{l}\text { Dry } \\
\text { cell } \\
\text { wt. } \\
\text { (g/L) }\end{array}$ & $\begin{array}{c}\mathrm{P}(3 \mathrm{HB}) \\
\text { content } \\
(w \mathrm{w} \%)\end{array}$ & $\begin{array}{c}\text { 3HBO- } \\
\text { DEG } \\
\text { titer } \\
(\mathrm{g} / \mathrm{L})^{\mathrm{a}}\end{array}$ & $\begin{array}{c}\text { 3HBO- } \\
\text { DEG } \\
\text { yield } \\
\text { (g/g-Glc) }\end{array}$ \\
\hline Batch $^{b}$ & $\begin{array}{c}\text { 500-ml shake } \\
\text { flask }\end{array}$ & 100 & LB & 20 & 48 & 5.9 & 43.7 & 4.32 & 0.22 \\
\hline Batch $^{c}$ & 250-ml mini jar & 100 & LB & 40 & 48 & 5.1 & 24.6 & 11.2 & 0.28 \\
\hline Fed-batch $^{d}$ & 250-ml mini jar & 100 & LB & 109 & 120 & 12.4 & 55.0 & 30.4 & 0.28 \\
\hline Fed-batch & 250-ml mini jar & 100 & TB & 186 & 120 & 77.3 & 81.3 & 34.0 & 0.18 \\
\hline Fed-batch & 250-ml mini jar & 100 & MR (Y5) & 119 & 120 & 11.9 & 67.6 & 23.8 & 0.20 \\
\hline Fed-batch & 2-L jar & 1,000 & LB & 120 & 96 & 26.2 & 44.6 & 34.8 & 0.29 \\
\hline
\end{tabular}

${ }^{a_{3} H B O-D E G}$ titer is described as volumetric weight excluding DEG.

${ }^{b}$ Data from previous study (Hiroe et al., 2021).

${ }^{c}$ Time course is shown in Figure 4.

${ }^{d}$ Time course is shown in Figure 6.

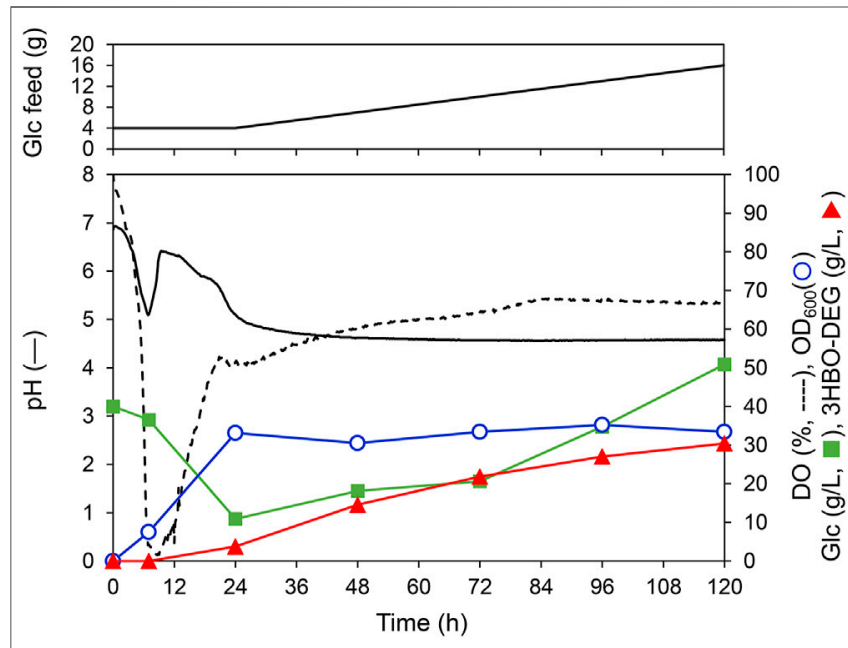

FIGURE 6 | Fed-batch culture of E. coli BW25113 $\Delta$ adhE harboring pGEM-phaRC ${ }_{\text {YB } 4} A B$ with a 250-ml mini jar fermenter. Cells were cultured at $30^{\circ} \mathrm{C}, 1 \mathrm{vvm}, 600 \mathrm{rpm}, \mathrm{pH}$ uncontrolled in LB medium (initial working volume, $100 \mathrm{ml}$ ) supplemented with $40 \mathrm{~g} / \mathrm{L}$ glucose and $50 \mathrm{~g} / \mathrm{L}$ DEG.

Additionally, glucose was fed at a constant rate of $1.25 \mathrm{~g}-\mathrm{Glc} /(\mathrm{L} \cdot \mathrm{h})$ following $24 \mathrm{~h}$ of cultivation. Triangles denote the extracellular $3 \mathrm{HBO}-\mathrm{DEG}$

concentration, squares denote the glucose concentration, circles denote cell growth $\left(\mathrm{OD}_{600}\right)$, the solid line denotes $\mathrm{pH}$, and the dashed line indicates dissolved oxygen (DO). value than that in the batch culture (Figure 4). In addition, DO and $\mathrm{OD}_{600}$ were almost unchanged at $24-120 \mathrm{~h}$ of culturing, thereby suggesting that the cells consumed glucose predominantly to produce oligomers. However, after $72 \mathrm{~h}$ of culturing, the glucose concentration in the culture broth increased owing to a decrease in glucose consumption. Finally, $11 \mathrm{~g}$ of the added $16 \mathrm{~g}$ glucose was consumed by the cells. To improve the efficiency of the oligomer yield, it would be necessary to supply glucose according to the cellular consumption.

High titers of oligomer production were also observed in TB and MR (Y5) media. Specifically, the TB medium showed excellent cell growth and $\mathrm{P}(3 \mathrm{HB})$ /oligomer production, with
$52 \%$ of the consumed glucose converted to the intracellular $\mathrm{P}(3 \mathrm{HB})$ and the secreted oligomer. In the case of LB medium, the conversion of glucose to $\mathrm{P}(3 \mathrm{HB}) /$ oligomer was only $37 \%$ (Table 1). For foaming during culture, TB medium tended to have more foaming than LB medium. In contrast, the MR (Y5) medium did not foam excessively. Even when utilizing the MR (Y5) medium, the relatively high 3HBO-DEG titer $(23.8 \mathrm{~g} / \mathrm{L})$ was achieved on fed-batch culture. Note that $\mathrm{P}(3 \mathrm{HB})$ accumulation levels were relatively high for the TB and MR (Y5) media (67.6-81.3 wt\%) when compared to the LB medium (up to $55.0 \mathrm{wt} \%$ ).

\section{Scaling up of 3HBO-DEG Production With a 2-L Jar Fermenter}

To confirm the reproducibility of $3 \mathrm{HBO}-\mathrm{DEG}$ production at a larger working volume of $1 \mathrm{~L}$, a $\mathrm{pH}$-uncontrolled fed-batch culture was performed using a $2-\mathrm{L}$ jar fermenter. In this culture, glucose was manually fed at regular intervals, and the glucose concentration was kept within 5-20 g/L for most of the culture time. As listed in Table 1, the 3HBO-DEG titer reached $34.8 \mathrm{~g} / \mathrm{L}$ after $96 \mathrm{~h}$ of culturing, yielding similar results to the 250-ml mini jar fermenter. Therefore, the reproducibility of $3 \mathrm{HBO}-\mathrm{DEG}$ production was confirmed with a larger jar fermenter, and scale-up production was shown to be feasible.

\section{CONCLUSION}

The 3HBO-DEG can be used as a macromonomer for the synthesis of PHA-based materials such as poly(3HBO-DEGurethane); however, the high production titer of $3 \mathrm{HBO}-\mathrm{DEG}$ has not been achieved. To enhance the cost-effectiveness of $3 \mathrm{HBO}-\mathrm{DEG}$ production, it is necessary to increase the titer of $3 \mathrm{HBO}$ in the culture broth. In this study, we optimized the culture conditions for 3HBO-DEG secretory production based on 250-ml mini jar-fermenters. Among the culture conditions tested, the agitation speed had a strong effect on the secretion of $3 \mathrm{HBO}-\mathrm{DEG}$, and the highest titer was obtained at $600 \mathrm{rpm}$. The $3 \mathrm{HBO}-\mathrm{DEG}$ titer was slightly 
higher in $\mathrm{pH}$-uncontrolled cultures than in $\mathrm{pH}$-stat cultures. The optimum temperature was $30^{\circ} \mathrm{C}$, and the osmotic effect of $\mathrm{NaCl}$ had no positive impact on $3 \mathrm{HBO}-\mathrm{DEG}$ production. $\mathrm{LB}$ and TB media showed higher titers of 3HBO-DEG than MR (Y1) and MR (Y5) media. The oligomers produced under the optimized batch culture conditions were composed of 2- to 7 mers $3 \mathrm{HB}$ terminated with DEG, as revealed through an ESI TOF-MS analysis. A 3HBO-DEG titer of $30.4 \mathrm{~g} / \mathrm{L}$ was achieved by feeding glucose in fed-batch culture with the LB medium. Furthermore, 3HBO-DEG production of $34.8 \mathrm{~g} / \mathrm{L}$ was achieved with a larger working volume of $1 \mathrm{~L}$ with a 2-L jar fermenter, and the reproducibility was confirmed. Thus, this study demonstrates the feasibility of the mass production of $3 \mathrm{HBO}$.

\section{DATA AVAILABILITY STATEMENT}

The original contributions presented in the study are included in the article, further inquiries can be directed to the corresponding author.

\section{REFERENCES}

Agus, J., Kahar, P., Abe, H., Doi, Y., and Tsuge, T. (2006). Molecular Weight Characterization of poly $[(R)-3$-hydroxybutyrate] Synthesized by Genetically Engineered Strains of Escherichia coli. Polym. Degrad. Stab. 91, 1138-1146. doi:10.1016/j.polymdegradstab.2005.07.006

Agus, J., Kahar, P., Hyakutake, M., Tomizawa, S., Abe, H., Tsuge, T., et al. (2010). Unusual Change in Molecular Weight of Polyhydroxyalkanoate (PHA) during Cultivation of PHA-Accumulating Escherichia coli. Polym. Degrad. Stab. 95, 2250-2254. doi:10.1016/j.polymdegradstab.2010.09.009

Baba, T., Ara, T., Hasegawa, M., Takai, Y., Okumura, Y., Baba, M., et al. (2006). Construction of Escherichia coli K-12 In-Frame, Single-Gene Knockout Mutants: the Keio Collection. Mol. Syst. Biol. 2, 2006-0008. doi:10.1038/ msb4100050

Förster, A. H., and Gescher, J. (2014). Metabolic Engineering of Escherichia coli for Production of Mixed-Acid Fermentation End Products. Front. Bioeng. Biotechnol. 2, 16. doi:10.3389/fbioe.2014.00016

Hiroe, A., Hyakutake, M., Thomson, N. M., Sivaniah, E., and Tsuge, T. (2013). Endogenous Ethanol Affects Biopolyester Molecular Weight in Recombinant Escherichia coli. ACS Chem. Biol. 8, 2568-2576. doi:10.1021/cb400465p

Hiroe, A., Sakurai, T., Mizuno, S., Miyahara, Y., Goto, S., Yamada, M., et al. (2021). Microbial Oversecretion of (R)-3-hydroxybutyrate Oligomer with Diethylene Glycol Terminal as a Macromonomer for Polyurethane Synthesis. Int. J. Biol. Macromol. 167, 1290-1296. doi:10.1016/j.ijbiomac.2020.11.083

Hyakutake, M., Tomizawa, S., Mizuno, K., Abe, H., and Tsuge, T. (2014). Alcoholytic Cleavage of Polyhydroxyalkanoate Chains by Class IV Synthases Induced by Endogenous and Exogenous Ethanol. Appl. Environ. Microbiol. 80, 1421-1429. doi:10.1128/aem.03576-13

Iliev, I., Vasileva, T., Bivolarski, V., Salim, A., Morel, S., Rabier, P., et al. (2018). Optimization of the Expression of Levansucrase L17 in Recombinant E. coli. Biotechnol. Biotechnological Equip. 32, 477-486. doi:10.1080/13102818.2018. 1431056

Kahar, P., Agus, J., Kikkawa, Y., Taguchi, K., Doi, Y., and Tsuge, T. (2005). Effective Production and Kinetic Characterization of Ultra-High-Molecular-weight poly [(R)-3-hydroxybutyrate] in Recombinant Escherichia coli. Polym. Degrad. Stab. 87, 161-169. doi:10.1016/j.polymdegradstab.2004.08.002

Leonardo, M. R., Cunningham, P. R., and Clark, D. P. (1993). Anaerobic Regulation of the adhE Gene, Encoding the Fermentative Alcohol Dehydrogenase of Escherichia coli. J. Bacteriol. 175, 870-878. doi:10.1128/jb.175.3.870-878.1993

Miyahara, Y., Hiroe, A., Tsuge, T., and Taguchi, S. (2019). Microbial Secretion Platform for 3-Hydroxybutyrate Oligomer and its End-Capped Forms Using

\section{AUTHOR CONTRIBUTIONS}

TS, SM, YM, AH, ST, and TT conceived the study. TS and SM performed the experiments, and TS and TT wrote the manuscript in consultation with SM, YM, AH, and ST. All authors read and approved the final manuscript.

\section{FUNDING}

This work was supported by the Japan Science and Technology Agency (JST)-MIRAI (JPMJMI17EC).

\section{ACKNOWLEDGMENTS}

The authors thank the Suzukakedai Materials Analysis Division (Tokyo Institute of Technology) for the ESI TOF-MS and NMR analyses and the National BioResource Project (NBRP) for providing E. coli BW25113 $\triangle a d h E$.
Chain Transfer Reaction-Mediated Polyhydroxyalkanoate Synthases. Biotechnol. J. 14, 1900201. doi:10.1002/biot.201900201

Mizuno, S., Sakurai, T., Nabasama, M., Kawakami, K., Hiroe, A., Taguchi, S., et al. (2021). The Influence of Medium Composition on the Microbial Secretory Production of Hydroxyalkanoate Oligomers. J. Gen. Appl. Microbiol. 67, 134-141. doi:10.2323/jgam.2020.09.002

Mohd Fadzil, F. I., Mizuno, S., Hiroe, A., Nomura, C. T., and Tsuge, T. (2018). Low Carbon Concentration Feeding Improves Medium-Chain-Length Polyhydroxyalkanoate Production in Escherichia coli Strains with Defective $\beta$-Oxidation. Front. Bioeng. Biotechnol. 6, 178. doi:10.3389/fbioe.2018.00178

Nduko, J. M., and Taguchi, S. (2021). Microbial Production of Biodegradable LactateBased Polymers and Oligomeric Building Blocks from Renewable and Waste Resources. Front. Bioeng. Biotechnol. 8, 1548. doi:10.3389/fbioe.2020.618077

Pohlmann, A., Fricke, W. F., Reinecke, F., Kusian, B., Liesegang, H., Cramm, R., et al. (2006). Genome Sequence of the Bioplastic-Producing "Knallgas" Bacterium Ralstonia eutropha H16. Nat. Biotechnol. 24, 1257-1262. doi:10.1038/nbt1244

Roman, D. L., Isvoran, A., Filip, M., Ostafe, V., and Zinn, M. (2020). In silico Assessment of Pharmacological Profile of Low Molecular Weight Oligo-Hydroxyalkanoates. Front. Bioeng. Biotechnol. 8, 584010. doi:10.3389/fbioe.2020.584010

Sivashankari, R., and Tsuge, T. (2021). "Development of Polyhydroxyalkanoate (PHA) and its Copolymers as a Possible "Cure" for the Plastic Pollution," in Environmental Pollution and Remediation. Environmental and Microbial Biotechnology. Editor R. Prasad (Singapore: Springer), 59-79. doi:10.1007/ 978-981-15-5499-5_3

Sudesh, K., Abe, H., and Doi, Y. (2000). Synthesis, Structure and Properties of Polyhydroxyalkanoates: Biological Polyesters. Prog. Polym. Sci. 25, 1503-1555. doi:10.1016/s0079-6700(00)00035-6

Suzuki, M., Tachibana, Y., and Kasuya, K.-i. (2021). Biodegradability of Poly(3-Hydroxyalkanoate) and Poly( $\varepsilon$-Caprolactone) via Biological Carbon Cycles in marine Environments. Polym. J. 53, 47-66. doi:10. 1038/s41428-020-00396-5

Taguchi, S., and Matsumoto, K. i. (2021). Evolution of Polyhydroxyalkanoate Synthesizing Systems toward a Sustainable Plastic Industry. Polym. J. 53, 67-79. doi:10.1038/s41428-020-00420-8

Tanadchangsaeng, N., Kitagawa, A., Yamamoto, T., Abe, H., and Tsuge, T. (2009). Identification, Biosynthesis, and Characterization of Polyhydroxyalkanoate Copolymer Consisting of 3-hydroxybutyrate and 3-Hydroxy-4Methylvalerate. Biomacromolecules 10, 2866-2874. doi:10.1021/bm900696c

Tomizawa, S., Hyakutake, M., Saito, Y., Agus, J., Mizuno, K., Abe, H., et al. (2011). Molecular Weight Change of Polyhydroxyalkanoate (PHA) Caused by the PhaC Subunit of PHA Synthase from Bacillus cereus YB-4 in Recombinant Escherichia coli. Biomacromolecules 12, 2660-2666. doi:10.1021/bm2004687 
Tsuge, T., Hyakutake, M., and Mizuno, K. (2015). Class IV Polyhydroxyalkanoate (PHA) Synthases and PHA-Producing Bacillus. Appl. Microbiol. Biotechnol. 99, 6231-6240. doi:10.1007/s00253-015-6777-9

Tsuge, T. (2016). Fundamental Factors Determining the Molecular Weight of Polyhydroxyalkanoate during Biosynthesis. Polym. J. 48, 1051-1057. doi:10. 1038/pj.2016.78

Utsunomia, C., Matsumoto, K. I., and Taguchi, S. (2017). Microbial Secretion of D-Lactate-Based Oligomers. ACS Sustain. Chem. Eng. 5, 2360-2367. doi:10.1021/ acssuschemeng.6b02679

Utsunomia, C., Saito, T., Matsumoto, K. i., Hori, C., Isono, T., Satoh, T., et al. (2017). Synthesis of Lactate (LA)-based Poly(ester-Urethane) Using HydroxylTerminated LA-based Oligomers from a Microbial Secretion System. J. Polym. Res. 24, 167. doi:10.1007/s10965-017-1325-1

Wang, F., and Lee, S. Y. (1997). Production of Poly(3-Hydroxybutyrate) by Fed-Batch Culture of Filamentation-Suppressed Recombinant Escherichia coli. Appl. Environ. Microbiol. 63, 4765-4769. doi:10.1128/aem.63.12. 4765-4769.1997
Conflict of Interest: The authors declare that the research was conducted in the absence of any commercial or financial relationships that could be construed as a potential conflict of interest.

Publisher's Note: All claims expressed in this article are solely those of the authors and do not necessarily represent those of their affiliated organizations, or those of the publisher, the editors, and the reviewers. Any product that may be evaluated in this article, or claim that may be made by its manufacturer, is not guaranteed or endorsed by the publisher.

Copyright (c) 2022 Sakurai, Mizuno, Miyahara, Hiroe, Taguchi and Tsuge. This is an open-access article distributed under the terms of the Creative Commons Attribution License (CC BY). The use, distribution or reproduction in other forums is permitted, provided the original author(s) and the copyright owner(s) are credited and that the original publication in this journal is cited, in accordance with accepted academic practice. No use, distribution or reproduction is permitted which does not comply with these terms. 